\title{
Brachytherapy in India - a long road ahead
}

\author{
Susovan Banerjee, MD!, Umesh Mahantshetty, MD, DNB², Shyamkishore Shrivastava, MD, DNB² \\ 'Department of Radiation Oncology, Vienna General Hospital, Vienna, Austria, ${ }^{2}$ Department of Radiation Oncology, Tata Memorial \\ Hospital, Mumbai, India
}

\begin{abstract}
Brachytherapy can play a very important role in the definitive cure by radiation therapy in India. However, except for in a handful of centres, the majority of hospitals use it only for intracavitary treatment. The most probable reasons for such are the lack of logistical resources in terms of trained personal and supporting staff, rather than lack of radiotherapy machines and equipment. In this article, the authors look into the various aspects of brachytherapy in India: from its beginning to present days. The authors point out the resources available, shortcomings, and some possible solutions to make use of brachytherapy more popular and effective. Apart from presenting a picture of the present scenario, the article pays attention to the positive signs of brachytherapy becoming more popular in the near future.

Key words: India, brachytherapy, challenges and promises.

\section{Purpose}

Brachytherapy by virtue of its characteristics, is the best form of conformal radiation therapy [1]. It has been noted that in a low and medium income country like India, there is huge shortage of basic radiation oncology equipment and manpower [2], hence the lack of upgraded machines and expertise for conformal teletherapy can easily be estimated. In such a country with a huge cancer burden and a lack of conformal teletherapy machines, brachytherapy can be very useful and effective in order to deliver the curative dose. However, for some reasons, brachytherapy is not practised to its full potential in India, barring a few premiere institutions. In this article, the authors attempt to present a comprehensive picture of brachytherapy in India: its evolution, existing facilities, research, and future prospects.

\section{Cancer burden in India and the prospects of brachytherapy}

India is the home to more than 1.2 billion people, and in 2012 approximately 1 million new cases of cancer and nearly 700000 deaths occurred in India due to this disease. In age-adjusted terms, the recorded incidence of cancer in India is at 94 per 100000 people [3]. The most common sites of cancer in men are the oral cavity, lung, oesophagus, and stomach. In women, the most frequent cancers are cervical, breast, and oral-cavity cancers. In urban registries (with the exception of Chennai), breast cancer is the most common type of cancer among women.
There are about 2.5 million cancer patients in India at any point of time [4]. About $50 \%$ of the newly diagnosed cases will require radiotherapy for their treatment.

The total incidences of cervical, breast, oral cavity, esophageal, and prostate cancer are about 0.4 million [3]. Brachytherapy may play a very important role in the management of these cancers. Some, like the penile cancer, are more amendable to brachytherapy in their early stage. Penis cancer has a high incidence rate of 3.4 in some rural places of India [5]. Sarcomas from all age groups, consists about a small 0.65 percent of total cancers in some regions [6]. Sarcomas are worth treating by brachytherapy, because of their more incidences in the lower age groups and the need for organ conservation.

There are certain advantages of brachytherapy that can be exploited in the Indian scenario: 1) optimal and precise conformal dose delivery; 2) normal tissue and organ adjacent to the region undergoing brachytherapy are spared of radiation effects due to sharp fall-off in the dose; 3 ) short duration of treatment. It would be an over simplification to say that the rule of thumb of brachytherapy technique is a simple time-dose relationship of 60 Gy in 6 days. But it is indeed a strong point in favour of brachytherapy in India, since the facilities of cancer treatment are mainly urban base. A large number of patients discontinue radiotherapy, because of travel or difficulties of staying away from home for a considerable period of time. Six to seven weeks of long travel and expenses associated with the above travel or stay are a burden for the patients [7]. Brachytherapy, if appropriately used, can increase treatment compliance and patient convenience. Most of the 
teletherapy facilities have a long waiting period. Optimum use of brachytherapy can decrease the waiting time of teletherapy in many hospitals.

Conformal techniques such as intensity modulated radiation therapy (IMRT), have been used in practice for the past two decades, and are now considered a necessity to deliver appropriate high dose to the tumour, sparing the surrounding normal tissues. Non conformal treatment with cobalt-60 $\left({ }^{60} \mathrm{Co}\right)$ teletherapy machines and simple LINACS still form the backbone of cancer treatment in several institutions of India. Brachytherapy can be the treatment of choice in these institutions to deliver the boost dose, reaching the curative dose, and maintaining tolerance of normal organs at the same time.

When it comes to organ preservation, the role of radiotherapy and especially brachytherapy becomes more important. With the increasing health care facilities in India and additional screening programmes, it is expected that more and more cancers will be detected at an earlier stage. This trend of early presentation is already notice-

Table 1. Milestones of brachytherapy development at the oldest comprehensive cancer centre of India,

Tata Memorial Hospital, Mumbai

\begin{tabular}{|c|c|}
\hline Year & Technology milestone \\
\hline 1941 & Radon seeds \\
\hline 1960 & $\begin{array}{l}\text { Preloaded }{ }^{137} \mathrm{Cs} /{ }^{60} \mathrm{Co} \text { capsules for intracavitary } \\
\text { irradiation }\end{array}$ \\
\hline 1962 & ${ }^{192} \mathrm{Au}$ grains for interstitial irradiation \& surface mould \\
\hline 1972 & Manual after-loading ${ }^{60} \mathrm{Co}$ \\
\hline 1976 & ${ }^{137}$ Cs tubes (BARC) indigenously developed \\
\hline 1979 & ${ }^{137} \mathrm{Cs}$ tubes/needles (Amersham) \\
\hline 1981 & $\begin{array}{l}{ }^{137} \text { Cs Selectron LDR/MDR (Nucletron) } \\
\text { PLATO treatment planning system (TPS) } \\
\text { Manual after loading }{ }^{192} \text { Ir for interstitial brachytherapy }\end{array}$ \\
\hline 1987 & ${ }^{192}$ Ir microSelectron LDR for interstitial brachytherapy \\
\hline 1994 & $\begin{array}{l}\text { microSelectron HDR } \\
\text { TPS - PLATO }\end{array}$ \\
\hline 1999 & $\begin{array}{l}\text { microSelectron - HDR control console } \\
\text { PLATO upgrade }\end{array}$ \\
\hline 2005 & $\begin{array}{l}\text { PLATO upgrade } \\
\text { Sunrise Workstation } \\
\text { Computer tomography (CT)/magnetic resonance(MR) } \\
\text { compatible applicators }\end{array}$ \\
\hline 2006 & Digitally networked C arm in the operating room \\
\hline 2008 & $\begin{array}{l}\text { Use of ultrasonography (USG) and (MR) in volume } \\
\text { delineation }\end{array}$ \\
\hline 2010 & $\begin{array}{l}\text { 3D brachytherapy } \\
\text { International collaboration on brachytherapy } \\
\text { protocols } \\
\text { Oncentra }{ }^{\oplus} \text { treatment planning system }\end{array}$ \\
\hline 2013 & Networking with PACS \\
\hline
\end{tabular}

${ }^{137} \mathrm{CS}$ - cesium-137, ${ }^{192} / \mathrm{r}$ - iridium-192, ${ }^{60} \mathrm{CO}$ - cobalt-60, ${ }^{192} \mathrm{Au}$ - Gold-192 able even in the rural populations [8]. There will be an increased chance of cure from the prospect of a higher $\mathrm{cu}-$ rative radical dose, and more needs and opportunities for organ preservation.

\section{History of brachytherapy in India and current infrastructure}

In India, during 400 year $\mathrm{BC}$, the Ayurvedas recognised cancer to be a separate disease entity. Even classification, symptoms, and treatment available were formulated [9]. Since that early period till the advent of European medicine, cancer was treated by the traditional systems of medicines. The first Department of Radiotherapy in India was opened on January 25, 1910 by the Countess of Minto at the Calcutta Medical College Hospital. The earliest cases were treated with deep X-ray and radium. The exact history of radium in India is not well known, but there are publications confirming that patients were treated in Kolkata with deep X-ray and radium brachytherapy by the year 1926 [10]. The bulk stock of radium arrived at Ranchi (Bihar), and then was transported to the Radium Institute Patna for clinical use in 1930. Over the years, 65 Indian hospitals had about 20 grams of radium in total, contained in the form of a fine powder in hundreds of thin platinum-iridium tubes and needles [11]. By the year 1941, Dr Ramaiah Naidu, a former associate of Madame Curie, had established the first radon plant of India at the Tata Memorial Hospital (TMH), Mumbai [12]. Until the beginning of the early 1960, there was a wide use of radium in the brachytherapy treatment of cancer along with deep X-rays [13]. From the beginning of the sixties, with installation of ${ }^{60} \mathrm{Co}$ machines in India [13], and also for reluctance of the physicians due to known side effects and hazards of radium, the use of brachytherapy was on a decline reflecting the World's mood. India imported caesium in the sixties. The exact milestones of procuring the sources and brachytherapy equipment by the different centres in India are difficult to trace. In order to understand its evolution, we can look at the landmarks of acquiring the brachytherapy equipments by the oldest comprehensive cancer institute in India i.e. TMH, Mumbai (Table 1) [12].

Atomic Energy Regulatory Board (AERB), the regulatory authority of India, reported in the early 2014 that there are 362 radiotherapy centres, equipped with 308 medical linear accelerators, 238 Telecobalt units, 4 Cyber Knife units, 3 Tomotherapy units, 8 Gamma Knife units, and 1 super-gamma unit. In addition to the above teletherapy units, there are $232 \mathrm{HDR}$ and 91 LDR brachytherapy units available in the different hospitals across the country. There has been an impressive growth of brachytherapy units and advancement of treatment technologies in the recent years. Figure 1 illustrates the sharp growth of brachytherapy (predominantly HDR) facilities in India keeping pace with teletherapy machines and needs since 2005 [14]. Most of the facilities in the corporate healthcare and upgraded government sectors have CT scanners simulators for RT planning, but unfortunately a survey regarding patterns of care of brachytherapy and its related details does not exists [15]. 


\section{Research and development of brachytherapy equipment in India}

The 'made in India' exercise of producing equipment was pioneered by Dr Naidu. With two grams of radium, he made thousands of radon seeds for treating cancer. From the primary stock of radium, radon can be "milked" and sealed into gold or glass seeds. By 1941, he had produced 3600 seeds for treatment [12].

At the beginning of the caesium era, the Government of India appointed an expert committee in consultation with Dr Dinshaw to aid and guide the manufacture of indigenous after loading caesium sources. The pilot project, which cost 250,000 USD, finally made India self sufficient to produce the after loading caesium kit by 1994 [16]. The country was also successful in making a remote after-loading cesium LDR unit at Chennai in 1995. The cost of the unit was less than one-fifth of the cost of an imported sophisticated unit [17].

The latest achievement in the field of brachytherapy self sufficiency includes the development of a remote controlled HDR machine and steel applicator in the country by the Board of Radiation and Isotope Technology (BRIT) [18]. Development of the treatment planning software for this homemade HDR brachytherapy unit has also been initiated. It will be a 16 channel brachytherapy machine for HDR treatment. The BRIT is also credited to be self sufficient in developing ${ }^{132} \mathrm{I}$ seeds for ocular and prostate brachytherapy [18]. The ocular brachytherapy part in India is practised both by the ophthalmologists and the radiation oncologists. They have been quite successful in the application of brachytherapy for treating the ocular malignancies [19].

\section{Training and educational materials for brachytherapy in India}

The Medical Council of India is responsible for accreditation of the degrees of specialisation in India, and they have made training of brachytherapy mandatory for the affiliated course. The teaching institute must have brachytherapy facilities for the course to be affiliated [20]. In spite of this compulsory posting with brachytherapy, the status of training on brachytherapy in most of the teaching centres is suboptimal. Although there are around 323 brachytherapy (232 HDR and 91 LDR) installations, more than two third of the institutions practise only intracavitary treatment (cervix, endometrium, and oesophagus) [21]. Hence, for most of the beginners pursuing training in radiotherapy, the knowledge on brachytherapy is theoretical, and brachytherapy practical experience, other than intracavitary procedure, is visibly lacking. Due to lack of advanced facilities in the past, the art of brachytherapy has been neglected in general. The number of conferences and workshops of national and state level importance focussed on brachytherapy are a handful. In 2013, two such courses of national importance were held with restricted participation. Out of the 15 teaching courses organised by the 'Indian College of Radiation Oncology (ICRO)' in the past 8 years for resident doctors, only one was focussed on compre-

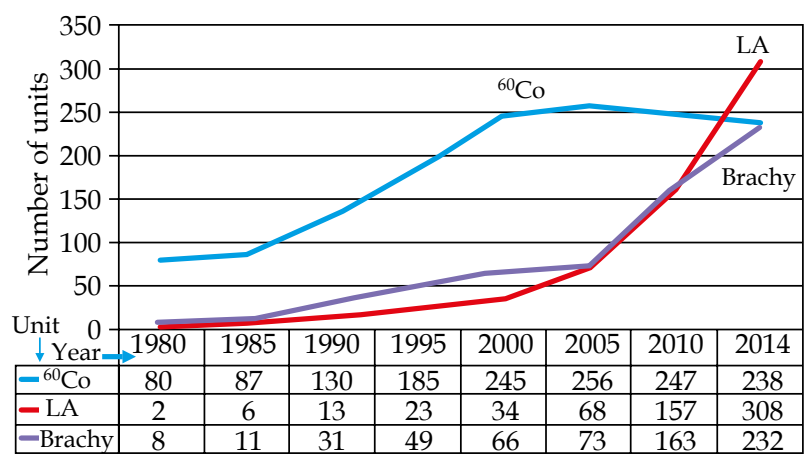

Fig. 1. Increase in the number of radiotherapy units in India

hensive brachytherapy. Generally, the interest to learn brachytherapy is satisfied by personal pursuance. In the annual conference of the 'Association of Radiation Oncologists of India (AROI)' of 2012, about 19 papers of original ongoing work focusing on brachytherapy were presented, out of a total of 198 presentations in all sections. However, in the recent past, there has been an increasing awareness and improvement for brachytherapy training. Various radiation oncology teaching bodies like AROI, ICRO, and the 'Indian Brachytherapy Society (IBS)', are trying to promote additional brachytherapy workshops and training programmes.

\section{Trends in comprehensive brachytherapy in India}

Brachytherapy in India is facing a number of challenges. Barring a few premiere institutes, most of the other Government run state hospitals and medical colleges lack dedicated operating theatres, anaesthetists, and equipment [22]. The patient to oncologist ratio in India is one per 16000 cancer patients [4]. As estimated, at present there is a deficit of 2186 radiation oncologists, 1217 medical physicists, and 3787 radiotherapy technologists in India [2]. Therefore, the chance of getting a personalised and individualised care such as brachytherapy remains a challenge in the less affluent centres. The corporate and private hospitals advertise and push for advanced radiation techniques like IMRT and IGRT, but not brachytherapy. The brachytherapy treatments are not a priority for reimbursements [23]

The latest developments in brachytherapy such as incorporation of newer imaging modalities (MR, PET), better brachytherapy applicators, powerful planning systems etc. with a potential to improve the therapeutic ratio have been successfully implemented in clinical practice of the developed world and the affluent centres of India. However, their implementation and wide practise across the bulk of centres in India will be a major challenge [24].

In spite of all these known and possibly many other unknown problems, the Indian radiation oncologists have kept the show running. In 1932, long before the standards of cervical cancer treatment were defined, one author from India claimed that teletherapy combined with brachytherapy should be the standard of care [10]. India has been a pioneer in proving equivalence of HDR with LDR in cervical cancer [25]. There are over 15 centres carrying out comprehensive brachytherapy practices for decades. 
The practices in those institutions have always been at par with that of the best centres in the world. For example, the international trial of image guided brachytherapy 'EMBRACE' has two of its participating institutions from India [26]. The Medical Council has recently increased the number of specialist courses to meet the growing demand [4], the country is going to have more trained anaesthetists and trained radiation oncologists in the near future. Moreover, additional number of university affiliated courses on medical physics and radiotherapy technology had come up in the recent days. The government is also funding more for up-grades and new equipments. With more installations of HDR machines, improved availability of applicators, availability of dedicated operating theatres, and anaesthesiologists, brachytherapy practices will see a revival in the right direction. One or two university accredited fellowship courses on the speciality of brachytherapy are ongoing [27]. To keep the interest growing, the 'Indian Brachytherapy Society' has been established on $16^{\text {th }}$ March 2006, with the main aim of promoting brachytherapy practice, training, and research. Each year annual conferences are being held with a strict focus on brachytherapy [28]. In the coming age of image guided radiotherapy, there may be a wave of change in the application and use of brachytherapy in India.

Indian researchers and authors have quite a lot of significant contributions to brachytherapy in the world literature. Indian institutions have been a very important source of experience in the field of gynaecological cancers. Extensive publications relating to treatment of gynaecological cancers by intracavitary, interstitial, and image guided brachytherapy are available [25,29-32]. The other well explored field is that of head and neck cancers, with the goal of delivering conformal therapy in the form of brachytherapy [33]. A quick look into the brachytherapy articles over the past few years gives a glimpse of their activity in the form of publications for diverse sites like anal cancers [34], early stage penile cancers [35], and even less explored organs such as the hepatobiliary malignancies [36-38]. There has been a surge in the quality and quantity of publications relating to brachytherapy from India in the last few years.

\section{The road ahead}

There is an urgent need to disseminate the knowledge and training from the elite institutions to the radiation oncologists and medical physicists working in the smaller centres. The national organisations like AROI, ICRO, and IBS can play a essential role in it this matter. Out of about a dozen national fellowships provided by the AROI each year, few have been reserved for brachytherapy. The IBS can take a crucial step in promoting brachytherapy works by coming up with a journal specifically focusing on brachytherapy. This may encourage people to undertake projects and hypotheses in the field of brachytherapy. All efforts for international collaboration with organisations like ESTRO, GEC-ESTRO, ASTRO, ABS etc. for bilateral exchange programs are ongoing. The global brachytherapy community should also consider similar steps. In India, where the skill of a doctor rather than technology takes the upper hand in patient care, brachytherapy is waiting for a renaissance.

\section{Disclosure}

Dr Susovan Banerjee is currently working as a clinical research fellow at $\mathrm{AKH} / \mathrm{MUW}$ on a research project funded by Elekta - Nucletron.

\section{References}

1. Polo A. Feasibility of functional imaging for brachytherapy. J Contemp Brachytherapy 2009; 1: 45-49.

2. Datta NR, Samiei M, Bodis S. Radiation therapy infrastructure and human resources in low- and middle-income countries: present status and projections for 2020. Int J Radiat Oncol Biol Phys 2014; 89: 448-457.

3. Mallath MK, Taylor DG, Badwe RA et al. The growing burden of cancer in India: epidemiology and social context. Lancet Oncol 2014; 15: 205-212.

4. Goss PE, Strasser-Weippl K, Lee-Bychkovsky BL et al. Challenges to effective cancer control in China, India and Russia. Lancet Oncol 2014; 15: 489-538.

5. Indian Council of Medical research. http://icmr.nic.in/cancer. pdf.

6. Gupta A, Rao HK, Gupta S. The incidence of soft tissue sarcoma in Dakshin Kannada: study in a District Government Hospital. Indian J Surg 2009; 71: 10-14.

7. Dutta S, Biswas N, Muhkherjee G. Evaluation of social-demographic factors for non compliance to treatment in locally advanced cases of cancer cervix in a rural medical college hospital in India. Indian J Pallat Care 2013; 19: 158-165.

8. Tiwari V, Shukla P, Gupta G. Changing trends of breast cancer awareness in young females of north India: A pilot study from a rural cancer hospital. Int J Med Public Health 2014; 4: 62-65.

9. Balachandran P, Govindarajan R. Cancer - an ayurvedic prospective. Pharmacol Res 2005; 51: 19-30.

10. Mitra S. Radiation therapy in carcinoma of the cervix uteri in India. Br J Radiol 1932; 55: 581-588.

11. Atomic Energy Regulatory Board, Application of radiation in medicine industry and research. http://www.aerb.gov.in/ AERBPortal/pages/English/t/sj/book/chapter9.pdf.

12. Shrivastava S. Brachytherapy - perspectives in evolution: take it with a bag of salt... J Can Res Ther 2005; 1: 73-74.

13. Gupta BD. Clinical practice of radiotherapy and oncology in India: past and present status. Int J Radiat Oncol Biol Phys 1996; 36: 945-947.

14. Atomic Energy Regulatory Board. http://www.aerb.gov.in/ AERBPortal/eLORA.htm.

15. Deshpande DD. Will MR image-guided brachytherapy be a standard of care for cervical cancer in future? An Indian perspective. J Med Phys 2012; 37: 1-3.

16. UNDP. Special Unit for Technical Cooperation among Developing Countries, Third World Academy of Sciences, Third World Network of Scientific Organizations. Fighting cancer with Cesium: India. In Sharing Innovative Experiences. Volume 1, Examples of Successful Initiatives in Science and Technology in the South. UNDP, Special Unit for Technical Cooperation among Developing Countries. http://tcdc2.undp. org/GSSDAcademy/SIE/VOL1.asp.

17. IEEE Xplore digital library. Indigenous development of a remote afterloading brachytherapy unit for the treatment of carcinoma of the cervix. http://ieeeexplore.us/xpl/tocresult.jsp?reload $=$ true\&sortType $\% 3$ Dasc_p_Sequence $\%$ 26filter\%3DAND(p_IS_Number\%3A11132)\%26rowsPerPage\%3D50\&pageNumber $=2$. 
18. Annual Report 2012-2013 Board of Radiation and Isotope Technology. http://www.britatom.gov.in/docs/pdf/ar_eng_12 _13.pdf.

19. Shah PK, Selvaraj U, Narendran V et al. Indigenous $125 \mathrm{I}$ Brachytherapy Source for the Management of Intraocular Melanomas in India. Cancer Biother Radiopharm 2013; 28: 21-28.

20. PG Syllabus for M.D (Radiotherapy). http://www.fmsc.ac.in/ curriculum/Curriculum\%20for\%20PG\%20\%20Radio\% 20Therapy.pdf.

21. Mohanty BK. The centenary of brachytherapy in clinical oncology. Natl Med J India 1998; 11: 10-12.

22. Thorat $\mathrm{P}$, Shidhave R, Goel G et al. Career choice influences in Indian Anaesthetisiologists: A cross sectional survey. Sri Lankan J Anaesthesiol 2011; 19: 43-48.

23. Munshi A. Resurrecting brachytherapy from brink of obliviation. J Can Res Ther 2011; 7: 391-392.

24. Mahantshetty U, Swamidas V, Engineer R et al. Implementation in clinical practice - challenges in developing economies. J Contemp Brachytherapy 2014; 6 (Suppl 1): 15.

25. Patel F, Sharma S, Negi P et al. Low dose rate vs. high dose rate brachytherapy in the treatment of carcinoma of the uterine cervix: a clinical trial. Int J Radiat Oncol Biol Phys 1993; 28: 335-341.

26. EMBRACE https://www.embracestudy.dk/ (accessed 04/ 06/14).

27. Bilimagga R. Resurrecting brachytherapy from brink of obliviation. J Can Res Ther 2012; 8: 329.

28. Indian Brachytherapy Society. http://www.indianbrachytherapy. com/

29. Nandwani P, Vyas R, Neema J et al. Retrospective analysis of role of interstitial brachytherapy using template (MUPIT) in locally advanced gynecological malignancies. J Can Res Ther 2007; 3: 111-115.

30. Mahantshetty U, Shrivastava S, Kalyani N et al. Templatebased high-dose-rate interstitial brachytherapy in gynaecologic cancers: A single institutional experience. Brachytherapy 2014; 13: 337-342.

31. Jamema S, Mahantshetty U, Tanderup K et al. Inter-application variation of dose and spatial location of $\mathrm{D}\left(2 \mathrm{~cm}^{3}\right)$ volumes of OARs during MR image based cervix brachytherapy. Radiother Oncol 2013; 107: 58-62.

32. Mahantshetty U, Jamema S, Khanna N et al. MRI-guided high-dose-rate intracavitary brachytherapy in cervical cancers at Tata Memorial Hospital: The initial clinical outcome. Brachytherapy 2009; 8: 112.

33. Mohanti B, Bansal M, Bahadur S et al. Interstitial brachytherapy with or without external beam irradiation in head and neck cancer: Institute Rotary Cancer Hospital experience. Clin Oncol (R CollRadiol) 2001; 13: 345-352.

34. Kapoor R, Khosla D, Shukla A et al. Dosimetric and clinical outcome in image-based high-dose-rate interstitial brachytherapy for anal cancer. Brachytherapy 2014; 13: 388-393.

35. Sharma D, Joshi N, Gandhi A et al. High-dose-rate interstitial brachytherapy for T1-T2-stage penile carcinoma: Short-term results. Brachytherapy 2014 [Article in press].

36. Aggarwal R, Patel F, Kapoor R et al. Evaluation of high-doserate intraluminal brachytherapy by percutaneous transhepatic biliary drainage in the palliative management of malignant biliary obstruction - a pilot study. Brachytherapy 2013; 12: $162-170$.

37. Sharma D, Thulkar S, Sharma S et al. High-dose-rate interstitial brachytherapy for liver metastases: first study from India. J Contemp Brachytherapy 2013; 5: 70-75.

38. Jain S, Kataria T, Bisht $\mathrm{S}$ et al. Malignant obstructive jaundice brachytherapy as a tool for palliation. J Contemp Brachytherapy 2013; 5: 83-88 